\title{
Mathematical Modelling the Ethnic System
}

\author{
Victor Korobitsin and Julia Frolova \\ Omsk State University, Computer Science Division, \\ 55A, Mira pr., 644077 Omsk, Russia \\ \{korobits, frolova\}@univer.omsk.su \\ http://www. univer.omsk.su/socsys
}

\begin{abstract}
The main of presented research is a demonstration of creating the society model on ethnic solidarity level. This model describes the behavior of ethnic system. The ethnic system includes a few ethnoses and provides their interactions. The interactions transmit by ethnic fields. The model is described by system of parabolic differential equations. The software TERRI is used for the forecast of arising the ethnic conflicts. Based on simulation result the researcher can compute the direction of ethnic field distribution and the most probable points of skirmish between ethnoses.
\end{abstract}

\section{Introduction}

The modelling of biosphere (ecological) processes gave rise to the research of society development. These models were destined for solving the problem of global change the ecological situation. Now the problem of interethnic conflicts is growing in society. It forces the international organizations to find the way for its adjustment. The modelling of global ethnic processes will allows to evaluate the world ethnic situation.

The aim of this research is the construction of mathematical model of ethnic field. The model is described by the system of parabolic equations. It is the tools for research the evolution of interactive ethnic systems under landscape influence.

\section{Ethnic Solidarity Level}

On the ethnosphere level the traditions play the special role in the society. The people get the behavior stereotypes from them. Thereby the general function of this level is the sample maintenance. The individuals strive for conservation of culture as a collection of history experience.

The ethnos is a people group, formed on basis of the original behavior stereotype. It exists as a energy system, opposing itself to other like groups. Thereby people are divided on own and alien man. The main ethnos attribute is a behavior stereotype. It is a complex of behavior standards of ethnos members. The collection of behavior stereotypes is defined by ethnic tradition differed the ethnos from biological population. 
The passio energy is an excess of biochemical energy of living substance. It suppresses the self-preservation instinct of man and defines the ability to goaldirected ultratension. The ethnic field is formed by the passio energy. It provides the interaction of ethnos members and regulates the joint goal-directed activity of their. Each ethnos forms the unique field and each ethnos member responds to this field. The behavior stereotypes, landscape, and culture values of ethnos characterize the field influence.

The primary motive for arising the ethnic conflicts is a skirmish of two not solidary ethnoses. The skirmish is an effect of distribution of some ethnic field on the territory of another ethnos. There are the territories occupied by the people of different ethnic systems. Such territory is a border or buffer zone placed between two ethnoses. The ethnic conflicts mostly arise on these zones. Therefore the actual problem is to discover the buffer zones and to forecast the ethnic conflicts. For this problem decision, we propose to use the methods of mathematical modelling. The model of level is created on the basis of Lev N. Gumilev's theory of ethnogenesis [1].

\section{Mathematical Model of Ethnic Field}

The ethnic system includes a few ethnoses and provides their interactions. The interactions is transmited by ethnic fields. This field is distributed on the landscape as hot gas in the space. We constructed the model of ethnic field from this analogy.

Consider the interaction of $k$ ethnoses in the field $G \subset R^{2}$ with boundary $\Gamma$. Let the passio energy of $i$ ethnos $\left(U_{i}\right)$ satisfies the energy conservation law in any given area. Define the passio energy density $u_{i}$ by

$$
U_{i}(t)=\iint_{G} u_{i}(x, y, t) d x d y .
$$

The ethnos state is defined by the passio tension. This characteristic is the ratio of passio energy volume to ethnos population quantity. The function $E(x, y, t)$ passio tension of ethnic field is constructed on base of the measurement strategy of history events frequency.

Interrelate the passio tension and density $u(x, y, t)$ of ethnic field energy by

$$
u(x, y, t)=k_{S} q(x, y, t) E(x, y, t),
$$

where $q(x, y, t)$ is the density of field receptivity by ethnos members, $k_{S}$ is the coefficient. The function $q(x, y, t)$ is defined by the relation

$$
Q(t)=\sum_{j} Q_{j}(t)=\iint_{G} q(x, y, t) d x d y,
$$

where the function $Q_{j}(t)$ describes the degree of receptivity and goal-directed use of passio energy by $j^{t h}$ ethnos member. The summation is made on all ethnos members fallen in $G$ area. 
Construct the integral balance equation describing change to density of ethnic field energy $u_{i}(x, y, t)$ of $i^{t h}$ ethnos $(i=1, \ldots, k), k$ is amount of ethnoses.

$$
U_{i}\left(t_{2}\right)-U_{i}\left(t_{1}\right)=\int_{t_{1}}^{t_{2}}\left[R_{i}(t)+P_{i}(t)+T_{i}^{+}(t)+T_{i}^{-}(t)+K_{i}(t)\right] d t
$$

where $U_{i}(t)=\iint_{G} u_{i}(x, y, t) d x d y$. The flows of passio energy are described by following expressions:

- $R_{i}$ is the passio energy inflowing in $G$ through boundary $\Gamma$,

$$
R_{i}(t)=\oint_{\Gamma} \varepsilon_{i}(x, y, t) \frac{\partial u_{i}}{\partial n}(x, y, t) d \gamma
$$

the coefficient $\varepsilon_{i}(x, y, t)$ characterizes the velocity of passio energy distribution.

- $P_{i}(t)$ is the passio energy inflowing in $G$ under the influence of directional moving energy through boundary $\Gamma$,

$$
P_{i}(t)=\oint_{\Gamma}-\left(\boldsymbol{a}_{i}, \boldsymbol{n}\right) u_{i}(x, y, t) d \gamma
$$

the vector field $\boldsymbol{a}_{i}$ gives the direction of energy moving, the vector $\boldsymbol{n}$ is exterior normal to boundary section $d \gamma$. Let rot $\boldsymbol{a}_{i}=0$ then the scalar function $\varphi_{i}$ exists and $\boldsymbol{a}_{i}=-\operatorname{grad} \varphi_{i}(x, y, t)$.

$-T_{i}^{+}(t)$ is inflow of passio energy under the induction process in $G$,

$$
T_{i}^{+}(t)=\iint_{G} \beta_{i}^{+}(x, y, t) u_{i}(x, y, t) d x d y
$$

the coefficient $\beta_{i}^{+}(x, y, t)$ is the velocity of induction process.

$-T_{i}^{-}(t)$ is outflow of passio energy to life support of ethnos members and landscape maintenance,

$$
T_{i}^{-}(t)=\iint_{G}-\beta_{i}^{-}(x, y, t) u_{i}(x, y, t) d x d y
$$

the coefficient $\beta_{i}^{-}(x, y, t)$ is the velocity of passio energy losses.

- $K_{i}(t)$ is outflow of passio energy under the skirmish of two ethoses,

$$
K_{i}(t)=\iint_{G}-\left(\sum_{j=1}^{k} \gamma_{i j}(x, y, t) u_{j}(x, y, t)\right) u_{i}(x, y, t) d x d y
$$

where $u_{j}$ is the density of passio energy of hostile ethnos, the coefficient $\gamma_{i j}(x, y, t)$ is the velocity of energy losses under the rivalry $i^{t h}$ and $j^{t h}$ ethnoses. The ratio $\gamma_{i i} u_{i}^{2}$ describes the internal conflicts in ethnos. 
The system of integral equations (1) is equivalent to the system of parabolic differential equations (add see [2])

$$
\frac{\partial u_{i}}{\partial t}=\frac{\partial}{\partial x}\left(\frac{\partial \varphi_{i}}{\partial x} u_{i}+\varepsilon_{i} \frac{\partial u_{i}}{\partial x}\right)+\frac{\partial}{\partial y}\left(\frac{\partial \varphi_{i}}{\partial y} u_{i}+\varepsilon_{i} \frac{\partial u_{i}}{\partial y}\right)+\left(\beta_{i}^{+}-\beta_{i}^{-}-\sum_{j=1}^{k} \gamma_{i j} u_{j}\right) u_{i}
$$

Define the initial and edge conditions for the system of parabolic equations by

$$
\begin{array}{ll}
u_{i}(x, y, 0)=u_{i}^{0}(x, y), & (x, y) \in G, \\
\frac{\partial u_{i}}{\partial n}(x, y, t)=0, & (x, y) \in \Gamma .
\end{array}
$$

Define the functions as follows:

- moving the passio energy

$$
\varphi_{i}(x, y)=\frac{\lambda_{i}}{2 \mu_{i}} e^{-\mu_{i}\left(\left(x_{i}^{0}-x\right)^{2}+\left(y_{i}^{0}-y\right)^{2}\right)}, \quad \lambda_{i}>0, \mu_{i}>0, \quad\left(x_{i}^{0}, y_{i}^{0}\right) \in G,
$$

- the passio energy distribution

$$
\varepsilon_{i}(x, y)=I_{G}\left(\xi_{\varepsilon_{i}} \circ l_{\omega}\right)(x, y), \quad l_{\omega}: \omega \rightarrow L, \quad \xi_{\varepsilon_{i}}: L \rightarrow R^{+},
$$

where $\omega$ is the discrete grid on $G$ area, $I_{G}$ is the interpolation operator of discrete functions on $\omega$ to continuous functions on $G, L$ is a set of landscape types,

- outflow of the passio energy

$$
\beta_{i}^{-}(x, y)=I_{G}\left(\xi_{\beta i} \circ l_{\omega}\right)(x, y), \quad \xi_{\beta i}: L \rightarrow R^{+},
$$

- inflow of the passio energy

$$
\beta_{i}^{+}(t)=\max \left\{0, \beta_{i}^{0}-\beta_{i}^{1} \cdot\left(t-T_{0}^{i}\right)\right\}, \quad \beta_{i}^{0}, \beta_{i}^{1} \in R^{+}, \quad T_{0}^{i} \geq 0,
$$

- the passio energy losses $\gamma_{i j} \in R^{+}$.

The system of parabolic differential equations (2) with the initial and edge conditions (3) is a mathematical model of ethnic field interactions.

Given model is a way for formalization of Lev N. Gumilev's theory. The model accentuates the energy and geographical aspects of theory and gives the clear formal description of internal processes.

\section{Simulation Tools TERRI for Modeling the Ethnic Fields}

The simulation tools TERRI is created for modeling of ethnosphere level. The tools realize the method for solving the system of parabolic differential equations that described the model of ethnosphere. The modeling result is demonstrated on the computer display as a dynamic map of ethnic fields. 
The initial data for modeling are the number of ethnoses $k$, map of landscapes, rates of changing the passio energy (functions $\varepsilon_{i}, \varphi_{i}, \beta_{i}, \gamma_{i j}$ ), initial distribution of passio energy density $u_{i}^{0}$.

Consider the simulation result of ethnosphere on real example. The aim of simulation was to define the landscape dependence of division of territory between ethnoses. The dependence is discovered on real geographical features of Europe, North Africa, and Middle East. Examine the interaction of three ethnic systems: West European, East Slavonic, Asia Minor. Each ethnos was described by the set of features (the function in the system (2)).

After run the modeling software TERRI, the map of landscapes is appeared on the display. On this map the different landscapes are marked by various colors. The ethnos is born in some point on the map. So the ethnic field is got the initial pulse. According to dynamic rule (2) the field is distributing on the landscape. The ethnic field is marked by color area on the display. Each ethnos has own color: first ethnos - blue, second - red, third - green. Given picture is demonstrated the distribution of ethnoses on the landscape. The value of passio energy density is shown by the brightness of color. The three stages of ethnos dynamics is shown on figure 1

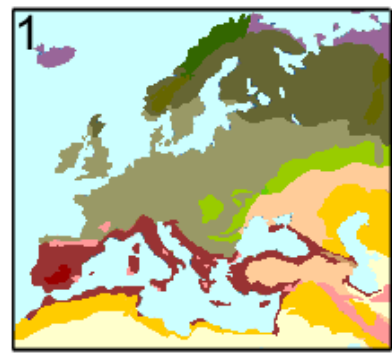

West European ethnos

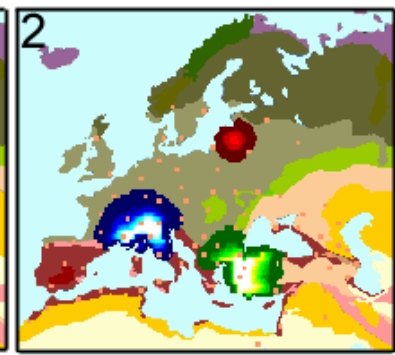

East Slavonic ethnos

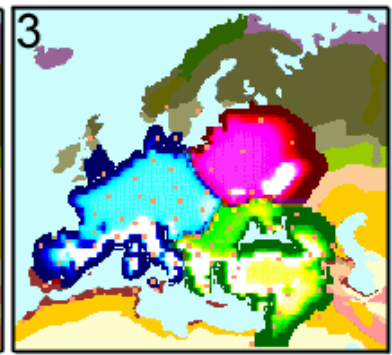

Asia Minor ethnos

Fig. 1. Distribution of ethnic fields

Initially the born ethnoses is developed on the isolation with each other. In time they come into collision observed by the ethnic field crossing. Under conflicts the passio energy of hostile ethnoses is loss. Since there are not solidary ethnoses then all they can not coexist on common territory. We can observe two way of conflict adjustment. Either the most powered ethnos forces out the feeble one or the equal-powered ethnoses separate the landscape. The buffer zone is formed between them.

The software TERRI allows doing a lot of tests with model. We fixed the part of initial parameters but were changed other parameters in various tests. We were getting the various pictures of ethnic dynamics. For analyzing the model behavior we was collecting the data of ethnos field distribution. The statistical analysis is demonstrated the dependence of ethnic field distribution on the landscapes. 
The simulation result is the statistical distribution of super-ethnoses on the landscape (figure 2).

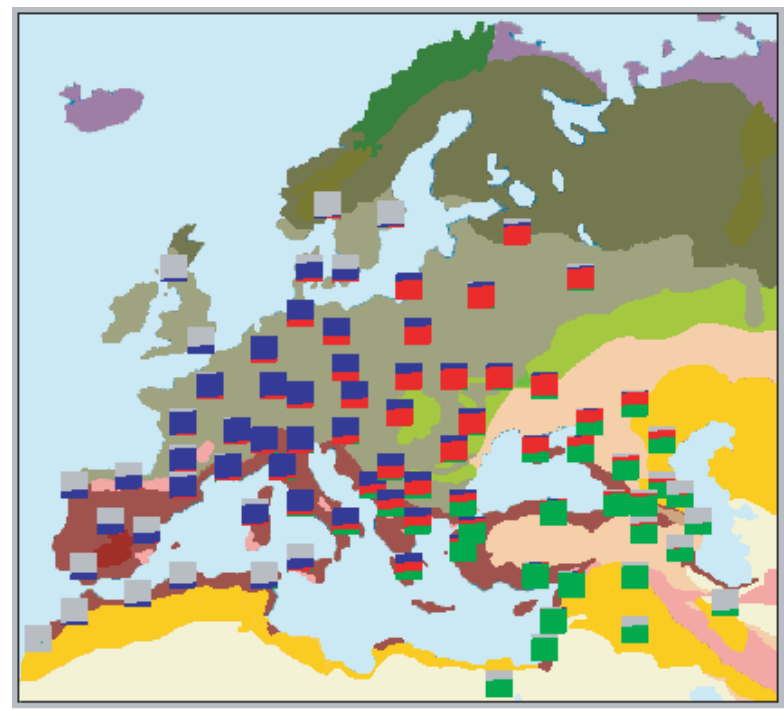

$1 \square \quad 2 \square \quad 3 \square \quad 4$

Fig. 2. Statistics of Ethnos Distribution

The comparative analysis of experimental data with the facts was made for the confirmation of hypothesis on ethnos distribution. The facts are the percentage composition of population by church in the cityes of region. These data was given from electronic library of Utrecht University, The Netherlands. The result of comparative analysis is shown on table 1 .

The cityes on table is sorted in ascending order of value $\Delta$. It is a deviation of experimental data from the facts, defined by

$$
\Delta=\frac{1}{2} \sum_{i=1}^{4}\left|a_{i}-b_{i}\right|,
$$

where $a_{i}$ is the facts, $b_{i}$ is the experimental data, $i$ is super-ethnos number.

The analysis of computer simulation results allows doing the following conclusions:

- the distribution of territories between ethnoses really depends on landscape;

- the obtained statistical data demonstrates the correlation of settling the ethnos on landscapes;

- the size of buffer zone is depended on the hostility of neighbor ethnoses. 
Table 1. Experimental Data vs the Facts. Church: I - Roman Catholic, II - Orthodox, III - Islam, IV - other; Super-Ethnos: 1 - West-European, 2 - East-Slavonic, 3 - Asia Minor, 4 - other.

\begin{tabular}{|l|rrrr|rrrr|r|}
\hline City & I & II & III & IV & 1 & 2 & 3 & 4 & $\Delta$ \\
\hline Paris & 89 & 4 & 3 & 4 & 87.2 & 8.0 & 0.0 & 4.8 & 4.8 \\
Andorra & 86 & 0 & 0 & 14 & 76.8 & 5.8 & 0.0 & 17.4 & 9.2 \\
Zagreb & 77 & 11 & 0 & 12 & 68.8 & 29.8 & 1.4 & 0.0 & 20.2 \\
Rome & 83 & 0 & 0 & 17 & 78.4 & 14.0 & 7.4 & 0.2 & 21.4 \\
Buchares & 6 & 80 & 0 & 14 & 22.8 & 71.6 & 5.6 & 0.0 & 22.4 \\
Minsk & 8 & 60 & 0 & 32 & 15.6 & 82.2 & 1.0 & 1.2 & 30.8 \\
Vienna & 85 & 0 & 0 & 15 & 64.8 & 35.2 & 0.0 & 0.0 & 35.2 \\
Saraevo & 15 & 31 & 40 & 14 & 49.2 & 32.2 & 18.6 & 0.0 & 35.4 \\
Sophia & 1 & 87 & 8 & 4 & 35.0 & 49.8 & 15.2 & 0.0 & 41.2 \\
Prague & 50 & 2 & 0 & 48 & 66.2 & 33.8 & 0.0 & 0.0 & 48.0 \\
\hline Berlin & 37 & 0 & 2 & 61 & 66.6 & 33.4 & 0.0 & 0.0 & 63.0 \\
Athens & 0 & 97 & 1 & 2 & 33.2 & 33.0 & 31.6 & 2.2 & 64.0 \\
Budapest & 68 & 0 & 0 & 32 & 35.6 & 64.0 & 0.4 & 0.0 & 64.4 \\
Tbilisi & 0 & 75 & 11 & 14 & 0.0 & 10.4 & 75.6 & 14.0 & 64.6 \\
Copenhagen & 1 & 0 & 0 & 99 & 60.0 & 11.8 & 0.0 & 28.2 & 70.8 \\
Jerusalem & 0 & 3 & 15 & 82 & 0.4 & 0.0 & 86.4 & 13.2 & 71.8 \\
Yerevan & 0 & 100 & 0 & 0 & 0.0 & 6.8 & 71.0 & 22.2 & 93.2 \\
\hline
\end{tabular}

\section{Conclusion}

We constructed the mathematical model of ethnic system. On results of presented research we can make up the following conclusions:

- this model is the tools for investigation in global development society area. Based on simulation result the researcher will have got the numerical evaluation of historical hypothesis on ethnosphere evolution;

- the software TERRI is used for the forecast of arising the ethnic conflicts. In that case, it is necessary to keep track of the passio energy pulse. Then we can compute the direction of ethnic field distribution and the most probable points of skirmish between ethnoses;

- one of the ways for ethnic conflict prevention is to fix the territory for certain ethnos. The landscape features characterized for this ethnos define these territories. So the separation of influence area of ethnos on territories is realized.

\section{References}

1. Gumilev, L.N.: Ethnogenesis and Biosphere of Earth. Tanais DI-DIK, Moscow (1994)

2. Guts, A.K., Korobitsin, V.V., Laptev, A.A., Pautova, L.A., Frolova, J.V.: Mathematical Models of Social Systems. Omsk State University Press, Omsk (2000) 